\section{Development, Growth and Ageing}

Edited by Nicholas Carter. Pp. 169, illustrated. Croom Helm, London, 1980. $£ 10.95$ (cloth £4.95).

This little book is based on preclinical courses in growth and development at the St George's Medical School. The contents include chapters on genetic and molecular aspects of development, physiological changes at birth, growth, puberty, biological theories of ageing and the development of language and the nervous system. The book is aimed at medical students but is of value to doctors in training, especially paediatricians. The format is clearly presented, easy to read and follow, and gives a basic uncomplicated approach. The book is not heavily referenced but rather a selection of suggested further reading is offered. This text can be recommended to students of biology in medicine and those with an interest in human development.

\section{The First Year of Life}

By H. B. Valman, with contributions from H. V. L. Finlay and J. F. Pearson. Articles published in the British Medical Journal. Pp. 85, illustrated. The British Medical Association, London, 1980. £5.00.

The First Year of Life is a collection of articles previously published as a series in the British Medical Journal. It should be of interest to those doctors who deal with children only infrequently but is of little value to the practitioner who sees children regularly; for him it represents merely an approach and outline. It is not aimed at the consultant or paediatrician in training. The contents include an approach to routine examination of the newborn and developmental surveillance at 6 and 8 months, and general discussion of things such as resuscitation and congenital abnormalities and common problems such as vomiting, feeding and weaning among others.

When originally published there was considerable correspondence, much of it critical, about individual sections but overall, while the approach is somewhat individualistic and possibly simplistic, it does provide a useful guide to the occasional paediatrician. The book is in the same format as the original articles with legible typeface and illustrations and no obvious typographical errors. It can be recommended to those who want a quick outline and approach to the first year of life but should not be regarded as approaching a textbook on this critical year.

\section{Fundamentals of Human Lymphoid Cell Culture}

By J. Leslie Glick. Pp. $\mathrm{x}+157$, illustrated. Marcel Dekker, New York, Basle, 1980. Sw.Fr. 52.00.

The establishment of cultures of lymphocyte cell lines now finds an application in many fields. This book covers the important aspects of the background of the techniques involved and goes on to discuss the properties of established cell lines and their biological characterization. Conditions for the initiation and maintenance of cultures are presented in detail with further chapters covering the preparation of media, the control of infection, storage and recovery. The sections on characterization include the preparation of chromosome smears, HLA typing and the recognition of lymphocyte subpopulations. The emphasis is on practicality, based on the author's long experience in the field. It is well referenced and clearly set out with a useful index. It will be an invaluable manual for the many bio-medical research workers of varied backgrounds who wish to turn to the use of cultured human lymphoid cells as a research tool. The principles and practices enunciated will also be of relevance to the management of many other cell lines and will find a ready application in such disciplines as immunology, virology, genetics, biochemistry and molecular biology.

\section{The House Physician's Handbook}

By C. Allan Birch, S. J. Surtees and Richard Wray. 5th edn. Pp. xv +299 , illustrated. Churchill Livingstone, Edinburgh, London and New York, 1980. £4.95.

There are currently 6 'guides' vying for the attention of the new house physician. The House Physician's Handbook, now in its fifth edition, is the oldest of them all and contains the wisdom of age and some of its frailties as well.

The book is divided into 6 sections. The first devoted to General Information gives clear and detailed advice on a host of bewildering situations for which Medical School will not have prepared the houseman - police and press enquiries and the various religious customs concerning the dead and dying. It is not taken for granted that all doctors working in British hospitals will have attended British Medical Schools and so be aware of local practice.

The Clinical Procedures and Medical Laboratory sections are sound, but sometimes lead to an unnecessary separation between technique and interpretation, as occurs for example in the case of arterial puncture for blood gases. It is, perhaps, odd that whilst the tyropericardial tapper is very properly advised to have someone with experience at hand for his first 'go', this does not seem to apply for anyone doing a pleural biopsy, a subclavian tap or passing a Sengstaken tube for the first time.

As the PMJ reviewer of the last edition found, the Treatment section is by far the weakest part of the book, betraying unfavourable aspects of the book's age. Fluid balance is derived from urinary chloride measurement and sodium status is taken to be represented by the plasma concentration. The advice given on infusion needs from a formula based on the plasma sodium concentration is likely to have the house physician sooner rather than later scurrying off to study the earlier well written sections on Medico-Legal advice. This also holds for advice on treating hypertensive crises with bolus injections of diazoxide and hyperkalaemic crises with frusemide.

Whilst on balance 'Birch' remains a useful book it must be used selectively and is perhaps more for the bookshelf than the white coat pocket.

\section{Inborn Errors of Metabolism}

Edited by Ronald Ellis. Pp. 105, illustrated. Croom Helm, London, 1980. £8.95 (paperback £3.50).

As a medical student one of the most difficult topics to understand is inborn metabolic errors with its implications in biochemistry, genetics and clinical medicine. This book, using simple and straightforward language, develops and explains to the non-expert physician and student of biochemistry and medicine the background, principles and major areas of relevance of the common inborn errors. There are chapters on the genetic basis and covering abnormalities in carbohydrate, lipid, mucopolysaccharide, amino acid, trace metal and purine and pyrimidine metabolism. There is useful clinical information and a discussion on the principles of diagnosis, dietary and other managements. The book does not claim to be comprehensive but does provide more than enough information for the average paediatrician and practitioner. One of the frustrating aspects is that people's names and references are mentioned in the text without there being a proper table of references to which to refer; only a list of suggested further reading is offered. The names of investigators mentioned only have relevance to the informed and not to the average reader. Overall it is a very useful book with well selected content, adequately indexed, easy to read and understand, and easy to recommend to students and practising physicians as a good basic guide to a very complex and rapidly changing area of medicine. 